\title{
Investigation of chromium carbide/alumina nano-composite prepared via MOCVD in fluidized bed and densification process
}

\author{
Hao-Tung Lin ${ }^{a}$, Wei-Sheng Huang ${ }^{a}$, Sheng-Chang Wang ${ }^{b}$, Horng-Hwa Lu ${ }^{c}$, \\ Wen-Cheng J. Wei ${ }^{\mathrm{d}}$, Jow-Lay Huang ${ }^{\mathrm{a}, *}$ \\ ${ }^{a}$ Department of Materials Science and Engineering, National Cheng Kung University, No. 1, Ta-Hsueh Road, Tainan 701, Taiwan, ROC \\ ${ }^{\mathrm{b}}$ Department of Mechanical Engineering, Southern Taiwan University of Technology, Tainan 710, Taiwan, ROC \\ ${ }^{\mathrm{c}}$ Department of Mechanical Engineering, National Chin-Yi Institute of Technology, Taichung 411, Taiwan, ROC \\ ${ }^{\mathrm{d}}$ Department of Materials Science and Engineering, National Taiwan University, Taipei 106, Taiwan, ROC
}

Received 9 June 2005; received in revised form 8 August 2005; accepted 8 September 2005

\begin{abstract}
Nano-sized Cr-species particles with a size about $20-40 \mathrm{~nm}$, uniformly coated on alumina particles, has been prepared by metal organic chemical vapor deposition (MOCVD) in the fluidized chamber, using the pyrolysis of $\mathrm{Cr}(\mathrm{CO})_{6}$ precursor. The Carbothermal reactions of $\mathrm{Cr}$-species in an $\mathrm{Ar}$ atmosphere in a graphite furnace at $1250^{\circ} \mathrm{C}$ for $2 \mathrm{~h}$ and the microstructure of high pressure sintering specimen are reported. The crystalline phase of the powder deposited in fluidized bed was characterized by an X-ray diffractometer, and transmission electron microscopy. The analysis indicates that the deposited powders were metastable $\mathrm{CrC}_{1-x}$ and $\mathrm{Cr}_{2} \mathrm{O}_{3}$. These $\mathrm{Cr}$-species were transferred into stable chromium carbide $\left(\mathrm{Cr}_{3} \mathrm{C}_{2}\right.$ and $\mathrm{Cr}_{7} \mathrm{C}_{3}$ ) after the thermal treatment as well as high pressure sintering. Microstructure of sintering specimen shows that the cluster of coating nano-particles were formed in the fluidized bed which coarsen during densification and generally located on the grain boundary to inhibit the alumina grain growth. Further, the independent coating nano-particle was also incorporated into the alumina grains.
\end{abstract}

(C) 2005 Elsevier B.V. All rights reserved.

Keywords: MOCVD; Alumina; Nano-particle

\section{Introduction}

Alumina $\left(\mathrm{Al}_{2} \mathrm{O}_{3}\right)$ is one of the most widely used ceramic materials because of its excellent physical, thermal and chemical properties, but its intrinsic brittleness and relatively poor reliability make the toughening of alumina ceramics an important and challenging area. Among the reported toughening methods [1-4], the incorporation of hard particulate reinforcement has been proven to be an easy, safe and economical toughening technique for alumina ceramics. Chromium carbide has been successfully incorporated into $\mathrm{Al}_{2} \mathrm{O}_{3}$ [1] for toughening purposes owing to its high Young's modulus and its high temperature erosion resistance. Quite promising mechanical properties and high temperature oxidation resistance of chromium carbide/alumina composites have been previously reported in the literature [1,5-7]. The advantages of the addition of ultrafine

\footnotetext{
* Corresponding author. Tel.: +886 6234 8188; fax: +886 62763586 .

E-mail address: JLH888@ mail.ncku.edu.tw (J.-L. Huang).
}

inclusions have been reported by Nakahira and Niihara [8]. These are the reduction in grain size of the matrix grains, and the strengthening and toughening of the composites. Various methods such as gas condensation [9], laser induced pyrolysis [10], sol-gel [11,12], microwave plasma [13] and gamma radiation [14] synthesis have been investigated for synthesizing nano-size particles. Furthermore, using traditional mixing techniques for preparing particle-reinforced composite, the nanoscaled reinforced particles are difficult to disperse uniformly on the micro-scale matrix particles. This problem is ascribed to the fact that nano-scale particles agglomerate easily due to the interaction between the particles. It was recognized [15] that a fluidized bed reactor can supply an environment with a uniform temperature and concentration of the coating precursor, which can provide the possibility of a good dispersion of reinforcing nano-particles in a matrix. A precursor vaporized at a low temperature is the major characteristic of the metal-organic chemical vapor deposition (MOCVD) process. The combination of conventional fluidized bed technology with standard chemical vapor deposition has been proven to be an effective method to 


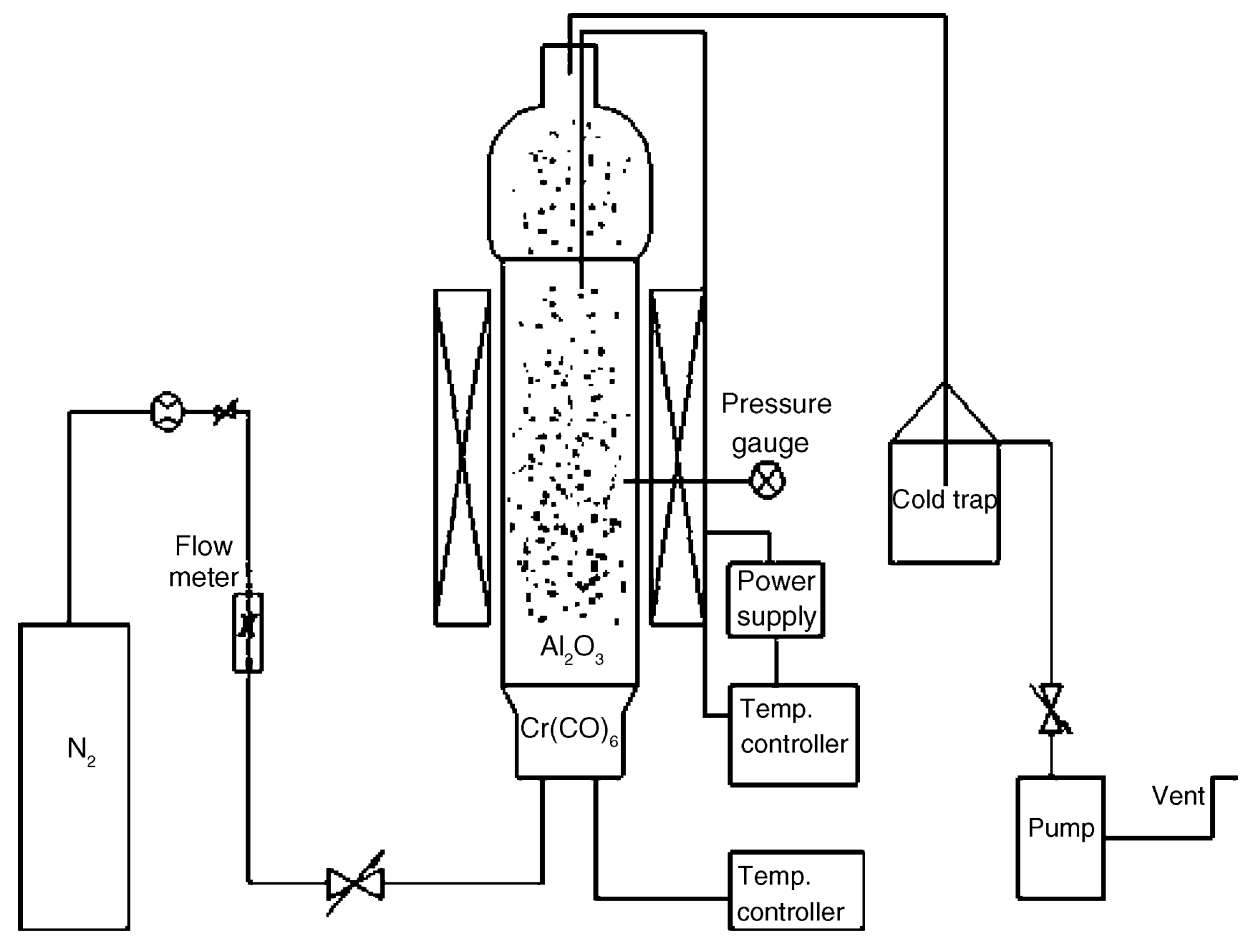

Fig. 1. Schematic diagram of MOCVD in fluidized bed reactor.

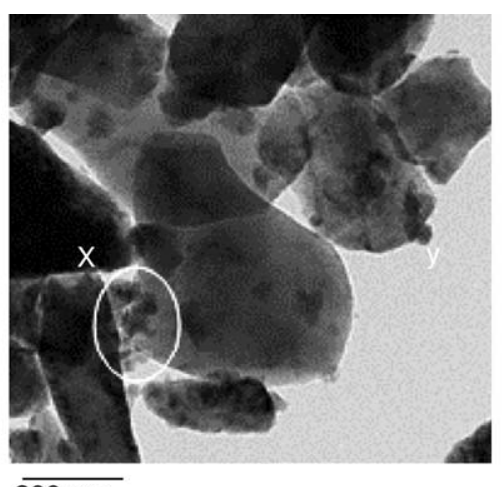

$\overline{200 \mathrm{~nm}}$

(a)

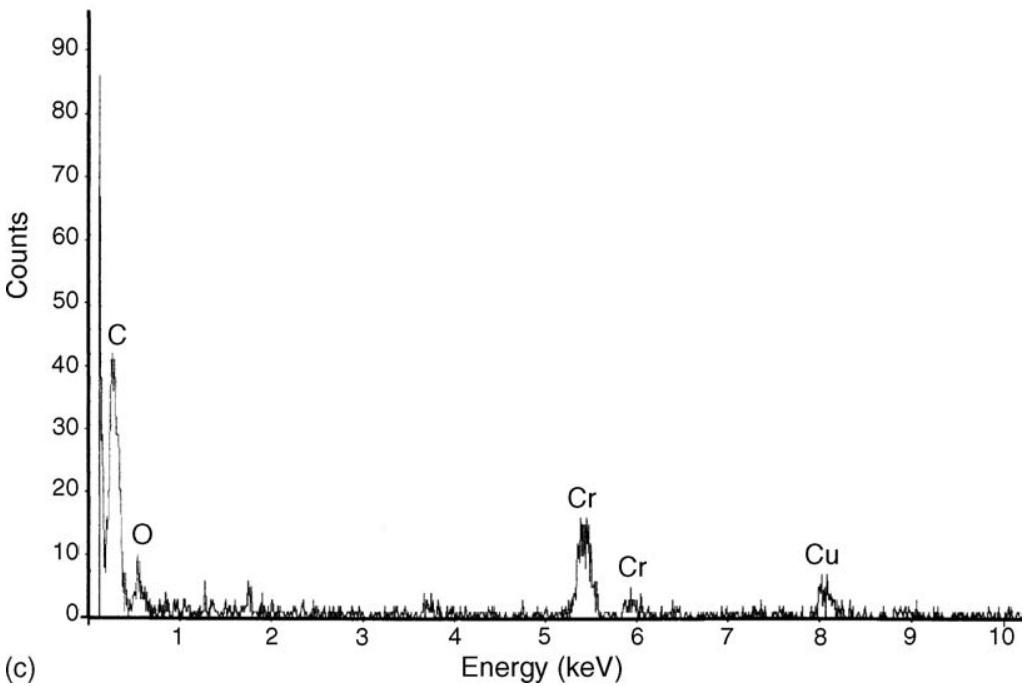

Fig. 2. (a and b) TEM micrographs of as-deposited particle prepared by MOCVD in fluidized bed at $400{ }^{\circ} \mathrm{C}$ in $\mathrm{N}_{2}$, showing the nano-sized Cr-species particles coated on micro-sized $\mathrm{Al}_{2} \mathrm{O}_{3}$ particle. " $\mathrm{x}$ " is a cluster nano-particles, " $\mathrm{y}$ " is a single nano-particle (c) EDS spectrum of the coating particle " $\mathrm{z}$ " in (b). 
deposit particles [16,17]. In this study, a fluidized powder reactor was used for MOCVD processes to produce the nano-sized particles coated on to $\mathrm{Al}_{2} \mathrm{O}_{3}$ particles with a micron grain size. The carbonizing of the nano-sized particles, the sintering behaviors and microstructure of the composites were also discussed in this study.

\section{Experiment}

Chromium hexacarbonyl $\left(\mathrm{Cr}(\mathrm{CO})_{6}, 99 \%\right.$, Strem Chemicals Co., USA) was used as a precursor for chromium oxide in the MOCVD process. Aluminum oxide powder (A16SG, Alcoa, USA) was used as the matrix powder. The vapor of the precursor was carried by $\mathrm{N}_{2}$ gas (99.9\% pure) that was introduced into the fluidized bed reactor for the MOCVD process.

Based on Lander's report [18], the precursor container was kept at $75^{\circ} \mathrm{C}$ in a vacuum (10 Torr) in the present study. Hexacarbonyl vapor, which was carried by $\mathrm{N}_{2}$ gas, was decomposed in the hot chamber (where the temperature was maintained at $400{ }^{\circ} \mathrm{C}$ ) and then the decomposed species would deposit on the fluidizing alumina particles. A schematic diagram of the apparatus is shown in Fig. 1.

The as-deposited particles were characterized by X-ray diffractrometry (Rigaku D/MaxII, Japan). Field Emission Transmission Electron Microscopy (FETEM, Hitachi FE-2000, Japan) equipped with energy dispersive X-ray spectroscopy (EDS, England) was used to identify phase, morphology and composition. The as-deposited powder was ball-milled for $24 \mathrm{~h}$ and sieved through a 200-mesh screen. The sieved powder was then thermally treated at $1250^{\circ} \mathrm{C}$ for $2 \mathrm{~h}$ in an $\mathrm{Ar}$ atmosphere in a graphite furnace. The ball-milled and screened powder, used as the sintering powder, was high pressed at $1400^{\circ} \mathrm{C}$ under a mechanical pressure of $25 \mathrm{MPa}$ for $1 \mathrm{~h}$ (High-multi-5000, Fujidempa Kogyo Co., LTD., Japan) under vacuum ( $10^{-3}$ Torr). The microstructure and phases of the sintered samples were also characterized by XRD, SEM (XL-40 FEG Field Emission Scanning Electron Microscope, Philip Co., Holland) and TEM. At least five samples were analyzed to acquire electron diffraction patterns and reliably identify the corresponding phases.

\section{Results and discussion}

\subsection{The characteristics of as-deposited powders}

TEM micrographs of the as-deposited powder prepared at $400{ }^{\circ} \mathrm{C}$ in the fluidized bed are shown in Fig. 2(a and b). Fig. 2(a) shows nano-particles disperses well on $\mathrm{Al}_{2} \mathrm{O}_{3}$ particles. Fig. 2(b) indicates that the nano-particles with about $20-40 \mathrm{~nm}$ were coated on $\mathrm{Al}_{2} \mathrm{O}_{3}$ particle. Fig. 2(c) is the EDS spectrum of the coating particle " $z$ " shown in Fig. 2(b), which clearly reveals the composition of $\mathrm{C}, \mathrm{Cr}$ and $\mathrm{O}$ elements. The $\mathrm{Cu}$ intensity coming from the $\mathrm{Cu}$ grid was also detected. The EDS results showed evidence that the coated particles resulted from pyrolysis coating by the Cr-precursor.

Fig. 3 shows the TEM diffraction pattern of nanometer-sized particles dispersed on the alumina surface of the particles as shown in Fig. 2(a). The TEM diffraction patterns, indicate that
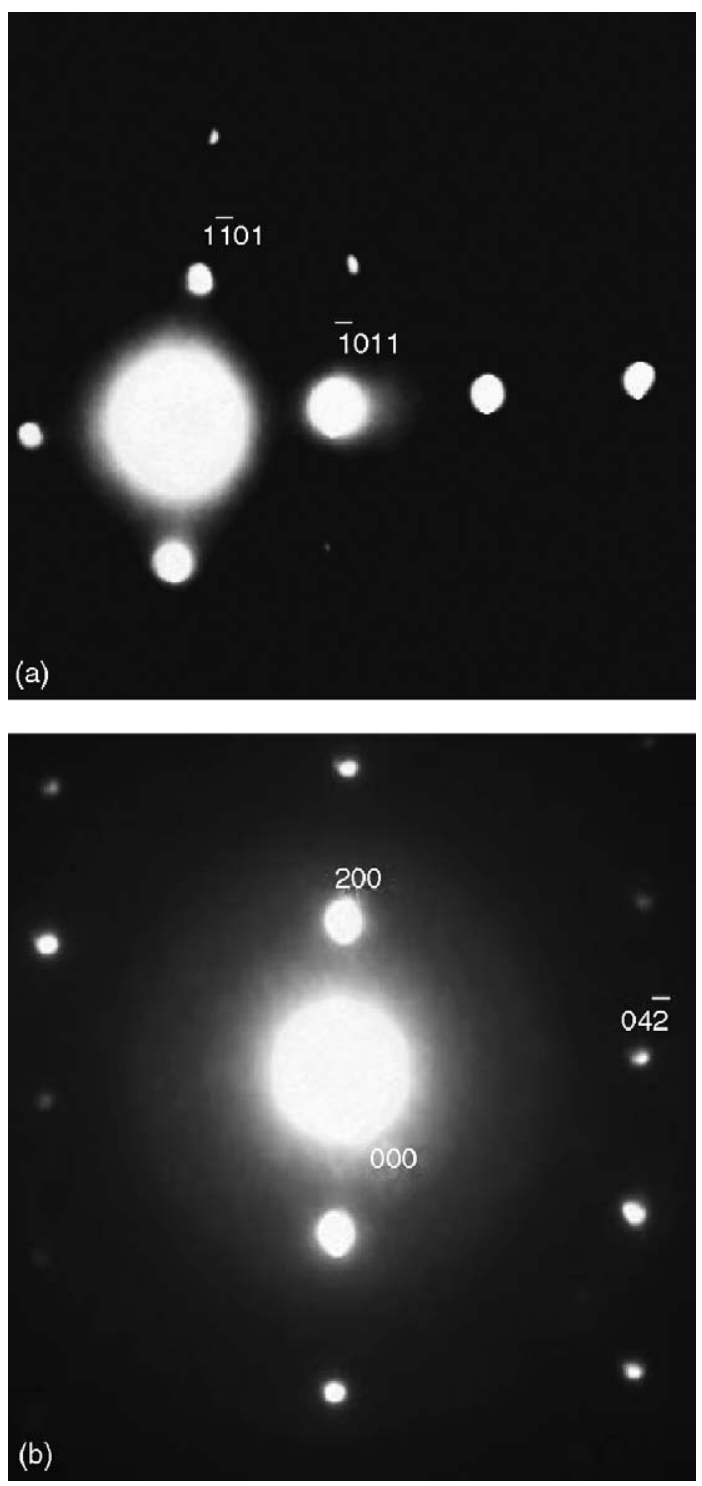

Fig. 3. TEM diffraction patterns of the coating particles of (a) $\mathrm{Cr}_{2} \mathrm{O}_{3}$ phase with hexagonal structure and (b) $\mathrm{CrC}_{1-x}$ phase with $\mathrm{NaCl}$ (B1) structure, respectively.

the coating particles were $\mathrm{Cr}_{2} \mathrm{O}_{3}$ with hexagonal crystalline structure and a $\mathrm{CrC}_{1-x}$ phase a with $\mathrm{NaCl}$ (B1) structure [19], as shown in Fig. 3(a and b), respectively. From our previous research [20], in addition to the chromium carbide $\left(\mathrm{CrC}_{1-x}\right)$, free carbon also existed in the as-deposited powder. These results are similar to the finding by Schuste and Maury [21]. They reported that the $\mathrm{CrC}_{1-x}$ phase was fabricated in the coating when $\mathrm{Cr}(\mathrm{CO})_{6}$ was used as the precursor of a MOCVD process. Bouzy et al. [19] indicated that non-stoichiometric $\mathrm{CrC}_{1-x}$ is a metastable phase, and interpreted that small $\mathrm{C}$ atoms were inserted in the octahedral interstitial sites of the cubic-close $\mathrm{Cr}$ packings in this structure.

\subsection{Carbothermal reaction of chromium-species}

Fig. 4 shows the TEM morphology and diffraction patterns of the as-deposited powder treated at $1250{ }^{\circ} \mathrm{C}$ for $2 \mathrm{~h}$ in an $\mathrm{Ar}$ atmosphere in a graphite furnace. Compared to the as-deposited 

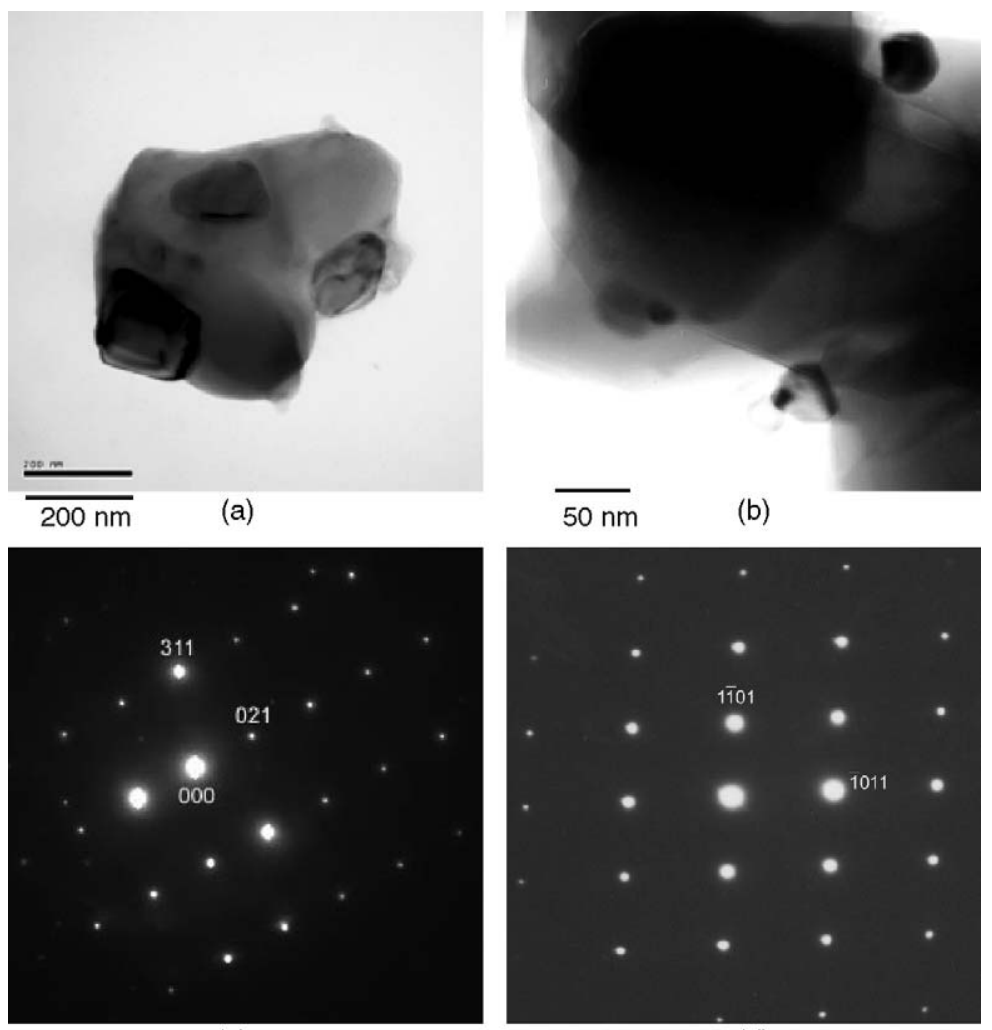

$$
50 \mathrm{~nm}
$$

(b)

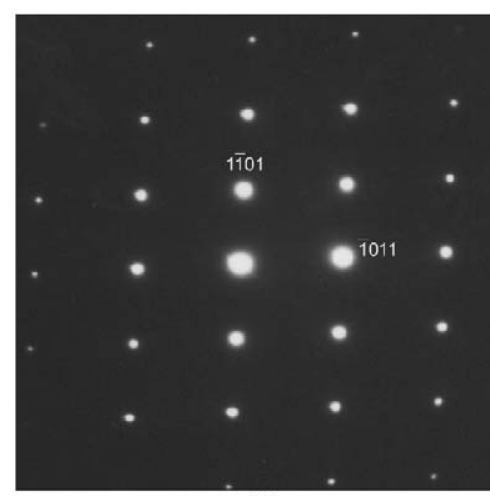

(d)

Fig. 4. (a and b) TEM micrographs of composite powder treated at $1250^{\circ} \mathrm{C}$ in a graphite furnace under an argon atmosphere for $2 \mathrm{~h}$, which the coating particles are about 100 and $30 \mathrm{~nm}$ in size, respectively. (c) TEM diffraction patterns of coating particles treated under above condition, showing a $\mathrm{Cr}_{3} \mathrm{C}_{2}$ phase with a orthorhombic structure and (d) showing a $\mathrm{Cr}_{7} \mathrm{C}_{3}$ phase with a hexagonal structure.

particles, the particle size shown in Fig. 4(a) increases from $20-40$ to $80-100 \mathrm{~nm}$. The growth was due to the coalescence of the cluster of nanometer-size particles as "x" in Fig. 2(a) during thermal treatment. Whereas the thermal treated particles shown in Fig. 4(b) keep the same size with the as-deposited, similar to the single coating particle like "y" in Fig. 2(a). Fig. 4(c and d) indicate the TEM diffraction patterns of coating particles, showing the $\mathrm{Cr}_{3} \mathrm{C}_{2}$ phase with an orthorhombic structure and the $\mathrm{Cr}_{7} \mathrm{C}_{3}$ phase with a hexagonal structure, respectively. Fig. 5 presents the XRD results for the powder heated under the thermal treatment, which is consistent with the observation made in the TEM diffraction patterns. It can thus be concluded that $\mathrm{Cr}_{7} \mathrm{C}_{3}$ and $\mathrm{Cr}_{3} \mathrm{C}_{2}$ form on the surface of the alumina after the heat treatment. In the case of the metastable $\mathrm{CrC}_{1-x}$ phase, according to the results of Bewilogua et al. [22], an annealing treatment would cause the transformation of the $\mathrm{CrC}_{1-x}$ into the stable $\mathrm{Cr}_{3} \mathrm{C}_{2}$. In this study, the $\mathrm{CrC}_{1-x}$ reacts with free carbon and can transform to $\mathrm{Cr}_{3} \mathrm{C}_{2}$. The carbonization of $\mathrm{Cr}_{2} \mathrm{O}_{3}$ has been previously explained [23-25]. Equations of the carbothermal reaction processes of $\mathrm{Cr}_{2} \mathrm{O}_{3}$ can be shown as following reactions [26]:

$\mathrm{Cr}_{2} \mathrm{O}_{3}+\frac{13}{3} \mathrm{C} \rightarrow \frac{2}{3} \mathrm{Cr}_{3} \mathrm{C}_{2}+3 \mathrm{CO}$,

$\Delta G=754746.567-543.87 T$

$$
\begin{aligned}
& \mathrm{Cr}_{2} \mathrm{O}_{3}+\frac{27}{7} \mathrm{C} \rightarrow \frac{2}{7} \mathrm{Cr}_{7} \mathrm{C}_{3}+3 \mathrm{CO}, \\
& \Delta G=757079.56-543.86 T
\end{aligned}
$$

Hernandez et al. [23] reported that the graphite mould introduced carbon radicals into the $\mathrm{Cr}_{2} \mathrm{O}_{3}$ powders, and promoted it conversion to $\mathrm{Cr}_{7} \mathrm{C}_{3}$ during thermal treatment to be carried out

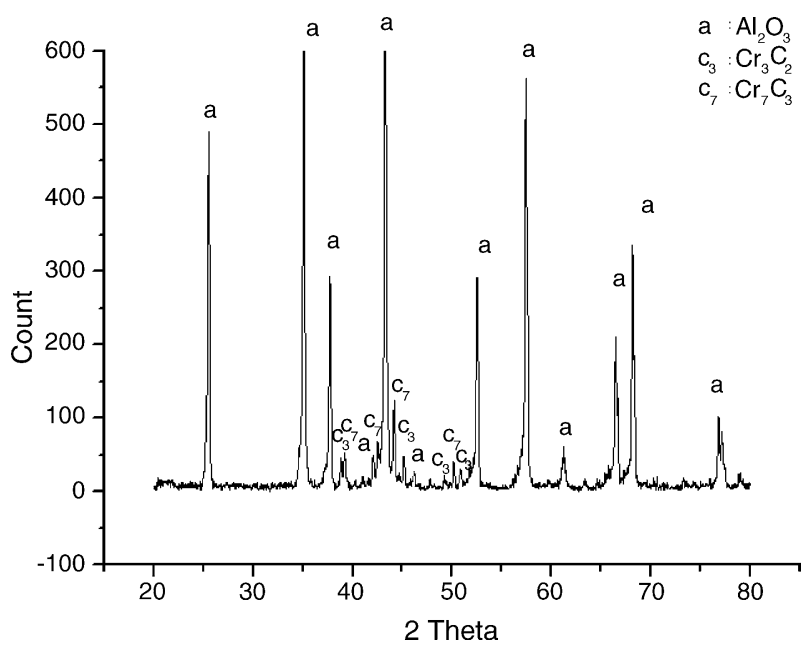

Fig. 5. XRD patterns of as-deposited powder at $1250^{\circ} \mathrm{C}$ for $2 \mathrm{~h}$ in an Ar atmosphere in a graphite furnace. 
Table 1

Carbon content of specimen

Fabricated in fluidized reactor

Carbon content (\%)

$400^{\circ} \mathrm{C}, 2 \mathrm{~h}$

0.23

in a graphite furnace. Chu and Rahmel [24] also suggested the carbonizing behaviors to be relevant to the activity of carbon. In their report, a piece of graphite felt was placed directly in front of the $\mathrm{Cr}_{2} \mathrm{O}_{3}$ tablet during thermal treatment and led to a greater formation of $\mathrm{Cr}_{3} \mathrm{C}_{2}$ surface particles, owing to the higher carbon activity in this system. Otherwise, the $\mathrm{Cr}_{7} \mathrm{C}_{3}$ phase would be generated during the carbonizing process. Antony et al. [25] also reported that the $\mathrm{Cr}_{3} \mathrm{C}_{2}$ phase was initially generated from the interface region between $\mathrm{Cr}_{2} \mathrm{O}_{3}$ and $\mathrm{C}$. In this study, the existence of a $\mathrm{Cr}_{7} \mathrm{C}_{3}$ phase was due to not all of the $\mathrm{Cr}_{2} \mathrm{O}_{3}$ particles in the fluidizing powder were directly in contact with the free carbon. Therefore, it is reasonable for the $\mathrm{Cr}_{3} \mathrm{C}_{2}$ and $\mathrm{Cr}_{7} \mathrm{C}_{3}$ phases to form simultaneously from the $\mathrm{Cr}_{2} \mathrm{O}_{3}$ particles during the thermal treatment (Table 1).

\subsection{Microstructure development of sintered samples}

The powder fabricated by the fluidized bed process at $400^{\circ} \mathrm{C}$ after the ball-milling and screening was used for hot-pressed sintering. Fig. 6 shows the XRD patterns of chromium carbide/alumina composite prepared by hot-pressing at $1400{ }^{\circ} \mathrm{C}$ in a vacuum for $1 \mathrm{~h}$. The peaks indicate the carbide phase was a mixture of phases of $\mathrm{Cr}_{7} \mathrm{C}_{3}$ and $\mathrm{Cr}_{3} \mathrm{C}_{2}$. The TEM micrograph of sintered chromium carbide/alumina nano-composites is shown in Fig. 7. The ratio of atom percentage between $\mathrm{Cr}$ and $\mathrm{Al}$ is expressed in Eq. (3):

$r=\frac{A_{\mathrm{Cr}}}{A_{\mathrm{Al}}}$

The atomic ratios $(r)$ of grains $\mathrm{A}-\mathrm{C}$ in Fig. 7 are shown in Table 2, which indicates that $\mathrm{Cr}$ ions diffused into the $\mathrm{Al}_{2} \mathrm{O}_{3}$ matrix and the $\mathrm{Cr}_{2} \mathrm{O}_{3}-\mathrm{Al}_{2} \mathrm{O}_{3}$ solid solution produced. According to the report of Sternitzke [27], the nano-sized particle (P)

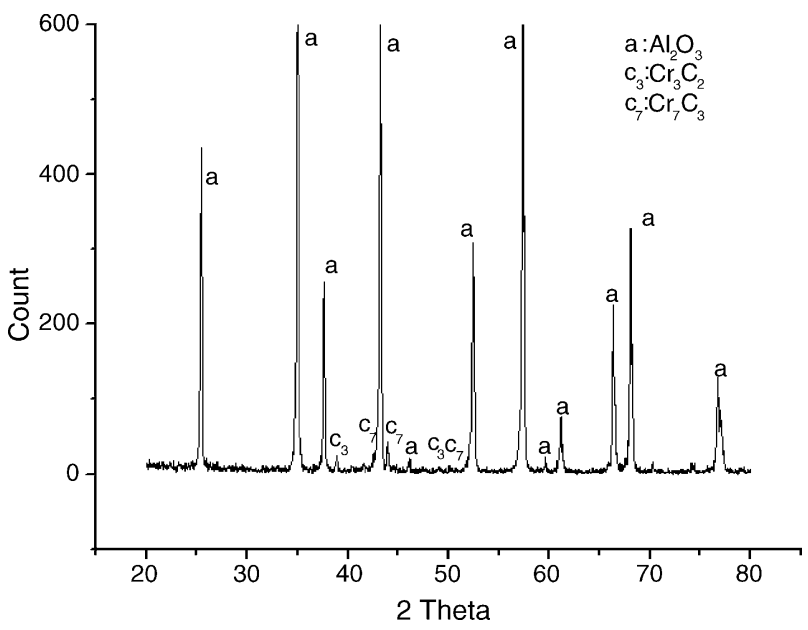

Fig. 6. XRD patterns of chromium carbide/alumina composite hot pressed at $1400^{\circ} \mathrm{C}$ in a graphite furnace in a vacuum for $1 \mathrm{~h}$.

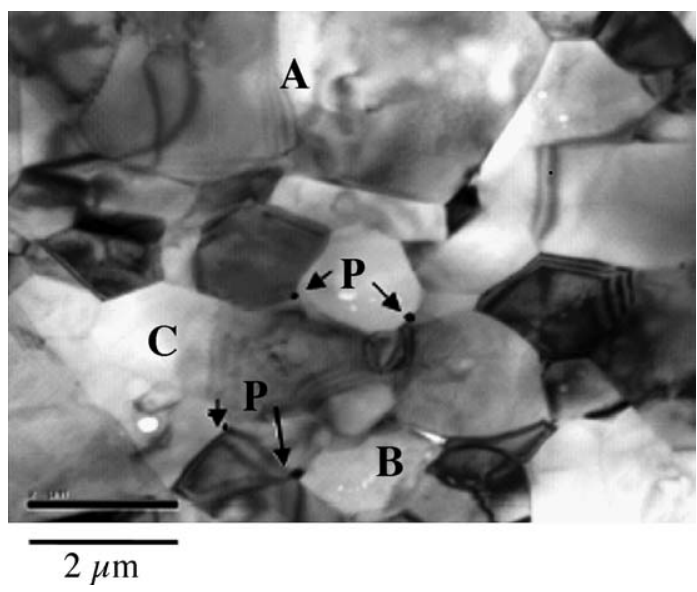

Fig. 7. Bright field image of TEM micrograph of chromium carbide/alumina nano-composite hot pressed at $1400^{\circ} \mathrm{C}$ in a vacuum for $1 \mathrm{~h}$.

shown in Fig. 7 pinned the matrix grain boundaries and inhibited the $\mathrm{Al}_{2} \mathrm{O}_{3}$ grain growth. Therefore, the $\mathrm{Al}_{2} \mathrm{O}_{3}$ grain nearby nano-sized particles as indicated in the figure, was smaller than others.

Fig. 8 shows the bright field image of TEM micrographs of sintered nano-composites. Fig. 8(a) shows the Cr-carbide particles marked "D" located on a triple junction. Fig. 8(b) is the higher magnification of Fig. 8(a). The dark field image is also shown in the right-upper corner of Fig. 8(b). It indicates that the particle " $D$ " is composed of nano-particles $d 1$ and $d 2$. A similar condition was also observed in Fig. 8(c and d), which show that "E" was composed of e1, e 2 and e3. The grain boundaries between the nano-particles were suspected to exist due to non-coalescence of grains in the final step of sintering. The nonconsolidation of nano-particles was ascribed to the pore easily becoming a residue in triple-junction area, which retards the coalescence of nano-particles. The intergranular chromium carbide particle with micron-size marked "F", as shown in Fig. 8(e) tended to stay at the triple-junction and suppressed the grain growth of the matrix because of the pinning force exerted on the grain boundary. It is similar to the reports [28,29], which indicates that the reinforced second phase led to narrower distribution of alumina grain size. Fig. 8(f) shows intragranular nano-sized particles, indicated by " $\mathrm{G}$ ", enclosed in an $\mathrm{Al}_{2} \mathrm{O}_{3}$ grain with a size of about $30 \mathrm{~nm}$, which approximately equals the original size of as-deposited powder fabricated in a fluidized bed. This implies that the nano-particles stop coarsening when they were trapped in the $\mathrm{Al}_{2} \mathrm{O}_{3}$ grain during sintering.

From the above discussion, it was found that the $\mathrm{Cr}_{2} \mathrm{O}_{3}$ particle had at least two reactions during sintering. One was that the system $\mathrm{Al}_{2} \mathrm{O}_{3}-\mathrm{Cr}_{2} \mathrm{O}_{3}$ formed due to the continuous solid

Table 2

Ratio ( $r$ ) of $\mathrm{Cr}$ to $\mathrm{Al}$ atom percentage on grains $\mathrm{A}-\mathrm{C}$ (in Fig. 7)

\begin{tabular}{ll}
\hline Grain & $r=A_{\mathrm{Cr}} / A_{\mathrm{Al}}$ \\
\hline $\mathrm{A}$ & $1.73 \times 10^{-2}$ \\
$\mathrm{~B}$ & $1.12 \times 10^{-2}$ \\
$\mathrm{C}$ & $0.86 \times 10^{-2}$ \\
\hline
\end{tabular}




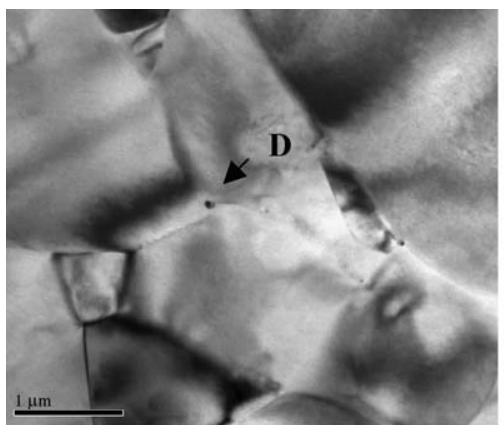

(a) $1 \mu \mathrm{m}$

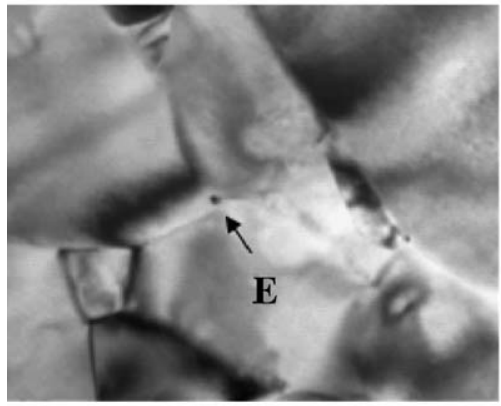

(c) $1 \mu \mathrm{m}$

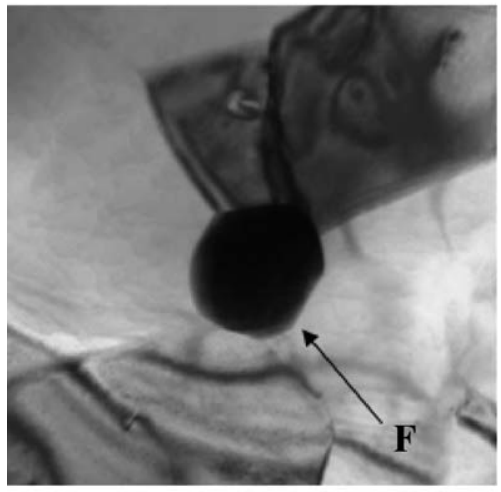

(e) $1 \mu \mathrm{m}$

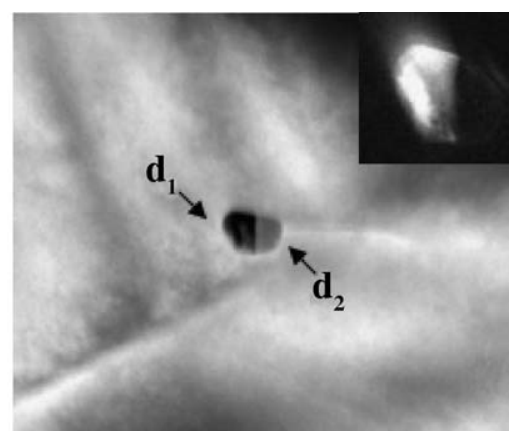

(b) $\overline{50} \mathrm{~nm}$

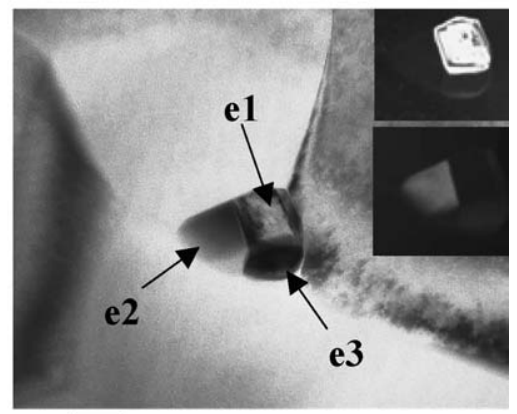

(d) $5 \overline{0 \mathrm{~nm}}$

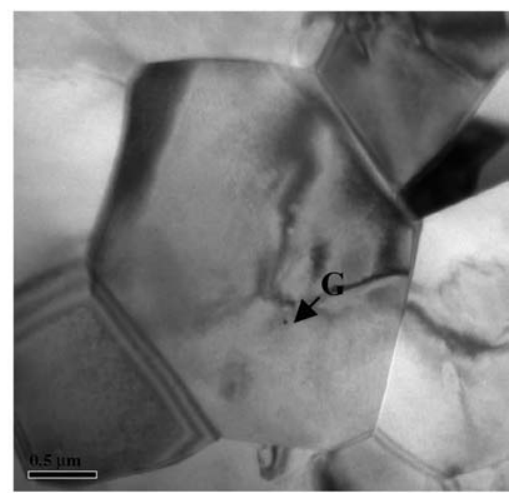

(f) $0 \overline{0.5 \mathrm{~mm}}$

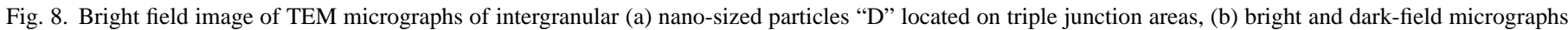

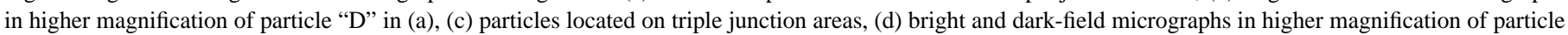
"E" in (c), (e) intergranular micron-sized particle "F" and (f) intragranular nano-sized particle "G".

solution in the system [30]. Another one was that $\mathrm{Cr}_{2} \mathrm{O}_{3}$ particles reacted with carbon or carbon radicals to induce $\mathrm{Cr}$-carbide $\left(\mathrm{Cr}_{3} \mathrm{C}_{2}\right.$ or $\left.\mathrm{Cr}_{7} \mathrm{C}_{3}\right)$.

\section{Conclusions}

A fluidized powder reactor used for MOCVD processes is an efficient method to prepare $\mathrm{Cr}$-species nano-powder/ceramic composite powders. Nano-sized $\mathrm{Cr}$-species particles were deposited uniformly on the surfaces of $\mathrm{Al}_{2} \mathrm{O}_{3}$ powders, which were ascribed to the characteristic of very large heat and mass transfer rates in the fluidized bed. The as-deposited powder with $\mathrm{CrC}_{1-x}$ and $\mathrm{Cr}_{2} \mathrm{O}_{3}$ was detected. The $\mathrm{CrC}_{1-x}$ transferred into a $\mathrm{Cr}_{3} \mathrm{C}_{2}$ phase during thermal treatment, while the $\mathrm{Cr}_{2} \mathrm{O}_{3}$ transferred to a mixture of $\mathrm{Cr}_{3} \mathrm{C}_{2}$ and $\mathrm{Cr}_{7} \mathrm{C}_{3}$. In case of $\mathrm{Cr}_{2} \mathrm{O}_{3}$ particles, there were two reactions that took place in the sintering process. One was the system $\mathrm{Al}_{2} \mathrm{O}_{3}-\mathrm{Cr}_{2} \mathrm{O}_{3}$ forming a solid solution, and the second one was the $\mathrm{Cr}_{2} \mathrm{O}_{3}$ particles reacting with carbon particles or carbon radicals to induce $\mathrm{Cr}$-carbide. Intergranular and non-consolidation nano-sized $\mathrm{Cr}$-carbide particles were observed at triple-junctions. In general, the coarse $\mathrm{Cr}$ carbide particles tended to located on grain boundaries, which impeded the alumina grain growth whilst nano-partilces which were incorporated into the alumina grains due to sintering of the nano-particles were probably pass over by the grain boundary movement associated with the typical densification mechanism.

\section{Acknowledgment}

The authors would like to thank the National Science Council of the Republic of China for its financial support under the Contract No. NSC-92-2216-E-006-011. 


\section{References}

[1] C.T. Fu, J.M. Wu, A.K. Li, J. Mater. Sci. 29 (1994) 2671-2677.

[2] S. Lio, M. Watanabe, M. Matsubara, Y. Matsuo, J. Am. Ceram. Soc. 72 (10) (1989) 1880-1884.

[3] W.J. Tseng, P.D. Funkenbusch, J. Am. Ceram. Soc. 75 (5) (1992) 1171-1175.

[4] Y.S. Chou, D.J. Green, J. Am. Ceram. Soc. 75 (12) (1992) 3346-3352.

[5] C.T. Fu, A.K. Li, J.M. Wu, J. Mater. Sci. 28 (1993) 6285-6294.

[6] K.M. Shu, C.T. Fu, D.M. Liu, J. Mater. Sci. Lett. 13 (1994) 1146-1148.

[7] C.T. Fu, A.K. Li, J.M. Wu, J.M. Wu, Br. Ceram. Trans. 93 (5) (1994) 178-182.

[8] A. Nakahira, K. Niihara, J. Ceram. Soc. Jpn. 100 (1992) 448-453.

[9] U. Balachandran, R.W. Siegel, Y.X. Liao, T.R. Askew, Nanostruct. Mater. 5 (1995) 505-512.

[10] G. Peters, K. Jerg, B. Schramm, Mater. Chem. Phys. 55 (1998) 197201.

[11] M. Chatterjee, B. Siladitya, D. Ganguli, Mater. Lett. 25 (1995) 261263.

[12] A. Kawabata, M. Yoshinaka, K. Horota, O. Yamaguchi, J. Am. Ceram. Soc. 78 (8) (1995) 2271-2273.

[13] D. Vollath, D.V. Szabó, J.O. Willis, Mater. Lett. 29 (1996) 271-279

[14] Y. Zhu, Y. Qian, M. Zhang, Mater. Sci. Eng. B41 (1996) 294-296.

[15] D. Kunii, O. Levenspiel, Fluidization Engineering, Huntington, NY, 1977, pp. 195-223.
[16] B.J. Wood, A. Sanjurjo, G.T. Tong, S.E. Swider, Sur. Coat. Tech. 49 (1991) 228-232.

[17] K. Tsugeki, T. Kato, Y. Koyanagi, K. Kusakabe, S. Morooka, J. Mater. Sci. 28 (1993) 3168-3172.

[18] J.J. Lander, L.H. Germer, Am. Inst. Min. Metall. Tech. 14 (6) (1947) $1-42$.

[19] E. Bouzy, E. Bauer-Grosse, G. Le Caer, Philos. Mag., B. 68 (5) (1993) 619-638.

[20] H.T. Lin, J.L. Huang, W.T. Lo, W.C.J. Wei, J. Mater. Res. 20 (8) (2005) 2154-2160.

[21] F. Schuste, F. Maury, Surf. Coat. Technol. 43 (1990) 185.

[22] K. Bewilogua, H.J. Heinitz, B. Rau, S. Schulze, Thin Solid Films 167 (1988) 233-243.

[23] M.T. Hernandez, M. González, A. De Pablos, Acta Mater. 51 (2003) 217-228.

[24] W.F. Chu, A. Rahmel, Oxid. Met. 15 (1981) 331-337.

[25] M.P. Antony, R. Vidhya, C.K. Mathews, U.V. Varada Raju, Thermochim Acta 262 (1995) 145.

[26] E.K. Storms, The Refractory Carbides, New York, London, 1967, p. 102.

[27] M. Sternitzke, J. Eur. Ceram. Soc. 17 (1997) 1061-1082.

[28] S. Maensiri, S.G. Roberts, J. Eur. Ceram. Soc. 22 (2002) 2945-2956.

[29] M. Sternitzke, E. Dupas, P. Twigg, B. Derby, Acta Mater. 45 (10) (1997) 3963-3973.

[30] R.C. Bradt, J. Am. Ceram. Soc. 50 (1) (1967) 54-55. 